\title{
Geochemistry of high concentrations of fluoride in groundwater at Oued Rmel aquifer (North-eastern Tunisia), and risks to human health from exposure through drinking water
}

\author{
MERIEM AMEUR ${ }^{1}$, FADOUA HAMZAOUI- AZAZA ${ }^{2}$ \\ ${ }^{1}$ meriem ameur@yahoo.fr,${ }^{2}$ fadoua hamzaoui@yahoo.fr
}

Tunisia is like most North African countries which are characterized by a harsh arid and semi-arid climate with scarce water resources and poor water quality on most of its territory. The quality of groundwater is not immune to pollution. In Tunisia, the origins of pollution can be natural, especially the geology of the region and the rocks type crossed by water but also the human activities always come to aggravate the situation.

The Oued Rmel aquifer, in Zaghouan city in north-eastern Tunisia, extends geographically between $36^{\circ} 18^{\prime}$ and $36^{\circ} 26^{\prime}$ North, and between $10^{\circ} 06^{\prime}$ and $10^{\circ} 24^{\prime}$ East. The groundwater of the Oued Rmel aquifer is exploited for drinking and irrigation purposes. To monitor the chemical water quality, and especially to identify the occurrence and behaviour of fluoride, 23 water samples were collected in January 2013, and analysed for chemicals parameters such as $\mathrm{Na}^{+}, \mathrm{Ca}^{2+}$, $\mathrm{Mg}^{2+}, \mathrm{K}^{+}, \mathrm{Cl}^{-}, \mathrm{SO}_{4}{ }^{2-}, \mathrm{HCO}_{3}{ }^{-}$and $\mathrm{F}^{-}$. This study applied conventional techniques such as hydrochemical compositions, multivariate statistical methods, Geochemical Modeling and Geographical Information Systems (GIS). Concentrations of fluoride in samples from the Oued Rmel aquifer ranged from 4 to $22 \mathrm{mg} / \mathrm{L}$. The highest values were observed in the surroundings of hydrothermal sources, especially from Hammam Zriba and Hammam Djedidi. Compared with international and national guidelines, all analysed samples exceeded the maximum permissible concentration, in drinking water, of WHO and Tunisian Standards (NT.09.14), which are 1.5 and $1.2 \mathrm{mg} / \mathrm{L}$, respectively. Consequently, up to $75 \%$ of the population in the region who use groundwater as a source of drinking water are at risk of developing dental or skeletal fluorosis. Thus, the treatment of fluoridated water through methods such as precipitation, ion exchange, electrodialysis, and reverse osmosis is essential.

Keywords: Fluoride; Human consumption; WHO; Oued Rmel aquifer; Dental and skeletal fluorosis ; Tunisia. 